\title{
Penerapan Metode Forward Chaining untuk Mendiagnosa Penyakit Tanaman Sawi
}

\author{
Ajeng Savitri Puspaningrum*, Erliyan Redy Susanto**, Adi Sucipto*** \\ *S1 Teknik Komputer, Fakultas Teknik dan Ilmu Komputer, Universitas Teknokrat Indonesia \\ ** S1 Sistem Informasi, Fakultas Teknik dan Ilmu Komputer, Universitas Teknokrat Indonesia \\ *** S1 Teknologi Informasi, Fakultas Teknik dan Ilmu Komputer, Universitas Teknokrat Indonesia \\ *ajeng.savitri@teknokrat.ac.id,**erliyan.redy@teknokrat.ac.id,*** adi.sucipto@teknokrat.ac.id
}

\begin{abstract}
Mustard greens is one of the plants that is very susceptible to disease. There is no type of mustard greens plant that is strong against disease or pests. In order to overcome or treat these diseases and pests, mustard greens farmers need to know the type of disease or pest that is attacking. But unfortunately, farmers' knowledge regarding mustard plant diseases is limited to the visible symptoms or the condition of the affected plant. The lack of knowledge of mustard greens farmer practitioners is due to the lack of counseling so that the presence of experts to help farmers is needed. Unfortunately, the experts are not always able to help if the condition requires fast handling because the number of experts are not many. In this study, this problem was resolved by developing a system equivalent to expert knowledge in detecting diseases in mustard plants. The system developed was a web-based system to detecting types of mustard disease automatically with the forward chaining method which can be used as an alternative to manual activities carried out by experts using 9 pests/diseases and 18 symptoms. The test results showed that the level of accuracy with expert expertise reaches $88.8 \%$
\end{abstract}

Keyword: Artificial Intelligence, Expert System, Forward Chaining, Mustard Green

\section{Introduction}

Salah satu kegiatan pertanian Indonesia, yang memiliki lahan pertanian yang luas, subur, dan iklim yang mendukung, adalah budidaya sayuran yang salah satu hasilnya yaitu sawi. Sawi hijau (Brassica juncea L.) merupakan tanaman semusim dan yang klasifikasinya dapat dijabarkan sebagai: Divisi: Spermatophyta; Subdivisi: Angiospermae; Kelas: Dicotyledonae Ordo: Rhoeadales (Brassicales); Keluarga: Cruciferae (Brassicaceae); Genus: Brassica; Jenis: Brassica juncea L. Batang sawi sangat pendek dan lebar sehingga hampir tidak terlihat yang berfungsi sebagai alat pembentuk daun dan penyangga [1]. Bentuk daun tanaman ini lonjong, halus, tidak berbulu dan tidak dipangkas yang pola pertumbuhannya tersebar sehingga menyulitkan pembentukan tanaman [2].

Sawi menjadi salah satu jenis sayuran berdaun yang mudah dibudidayakan, serta memiliki prospek yang baik dalam upaya meningkatkan pendapatan petani dan gizi bagi masyarakat. Namun, dalam proses budidaya masih terdapat gangguan yang disebabkan oleh penyakit sehingga dapat merusak tanaman tersebut seperti hama, mikroorganisme dan lain sebagainya. Hal tersebut berpotensi menurun-kan produktivitas tanaman sawi, bahkan dapat menyebabkan gagal panen [3]. Ada 9 penyakit tanaman sawi yang digunakan dalam penelitian ini diantaranya adalah ulat perusak daun (Plutella xylostella L.) [4], ulat tanah (agrotis ipsilon) [5], ulat grayak (Spodoptera litura) [4], penambang daun [6], penyakit busuk daun (Phytotora sp.) [7], akar gada [8], bercak daun [9], alternaria [10] dan kutu daun [11].

Sayangnya petani sawi hanya bisa melihat gejala penyakit atau kondisi tanaman akibat minimnya penyuluhan bagi petani sawi hal tersebut menyebabkan perlunya bantuan tenaga ahli untuk mengenali jenis penyakit yang menyerang tanaman sawi. Namun tenaga ahli tersebut tidak selalu dapat membantu jika kondisi membutuhkan waktu penanganan yang cepat mengingat jumlah tenaga ahli yang ada sedikit serta memiliki kesibukan masing-masing. Untuk mengatasi masalah pertanian, saat ini telah dikembangkan berbagai sistem pakar. Penerapan sistem pakar dipandang sebagai cara untuk mengimplementasikan pengetahuan para ahli/pakar pada bidang tertentu ke dalam suatu program sehingga dapat mengambil keputusan dan membuat penalaran yang cerdas [12].

Untuk tanaman sawi sendiri, sistem pakar telah dikembangkan menggunakan metode Bayes [3] dengan menggunakan 5 jenis penyakit sawi dan 11 gejala. Namun, hasil penelitian Siahaan [13] menunjukkan bahwa Forward Chaining dapat mendiagnosis penyakit lebih baik dibanding Metode Bayes. Oleh karena itu, untuk membantu para petani sawi mendiagnosa penyakit tanaman sawi lebih baik dengan variasi yang lebih 
banyak dibanding penelitian sebelumnya tanpa menunggu keterlibatan pakar secara langsung, dalam penelitian ini sistem pakar untuk mendiagnosis sawi dikembangkan mengguna-kan metode forward chaining berdasarkan pengetahuan seorang pakar pertanian dengan menggunakan 9 jenis penyakit dan 18 gejala.

\section{Research Method}

\subsection{Tahapan Penelitian}

Penelitian ini akan dilakukan dengan beberapa tahap yang dapat dilihat pada Gambar 1.

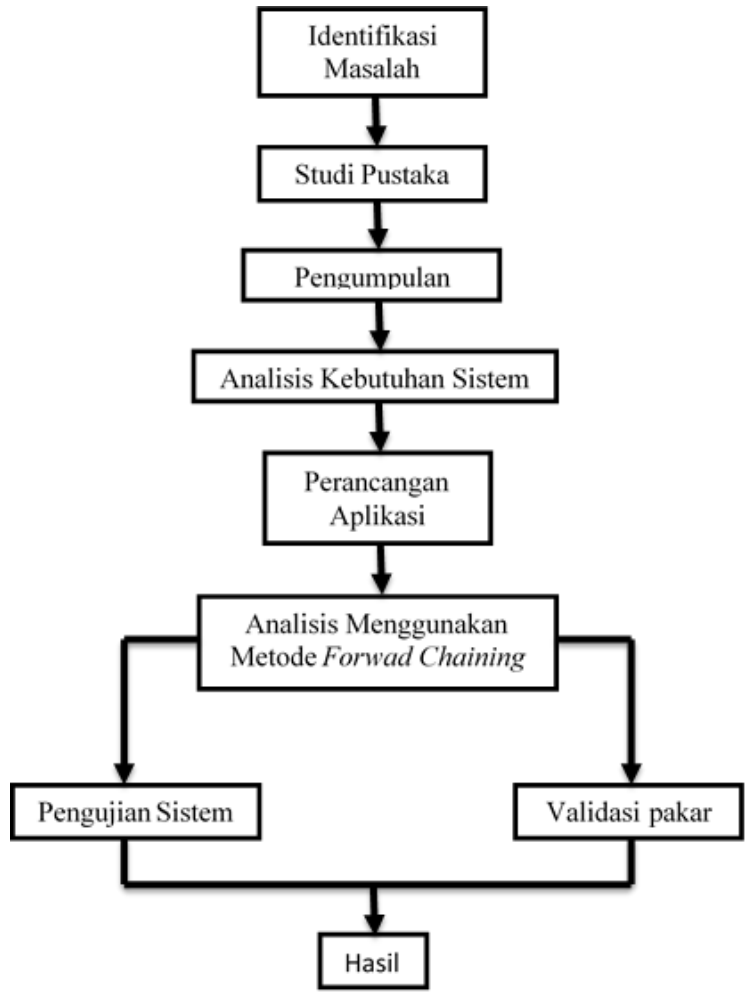

Gambar 1. Tahapan Penelitian

Penelitian ini dilakukan pada sebuah ladang pertanian di Bandar Lampung dengan melibatkan seorang pakar pertanian untuk mendapatkan pengetahuan terkait penyakit sawi.

\subsubsection{Karakteristik data}

Data mentah didapat dari seorang pakar yaitu, data gejala dan data penyakit serta solusi penanganannya. Selanjutnya dilakukan Analisis Data. Proses ini peneliti menganalisa data yang diperoleh dari informasi yang didpat dari proses pengumpulan data yang bersumber dari seorang pakar. Dari data tersebut dibuat alur dari setiap gejala-gejala menjadi suatu jenis penyakit, penyakit yang sering terjadi dapat dilihat pada Tabel 1 sedangkan penyakit tanaman sawi dan gejala-gejala yang berbeda dapat dilihat pada Tabel 2.

Tabel 1. Jenis penyakit Tanaman Sawi

\begin{tabular}{cl}
\hline Kode Penyakit & \multicolumn{1}{c}{ Jenis Penyakit } \\
\hline P01 & Ulat perusak daun \\
\hline P02 & Ulat tanah \\
\hline P03 & Ulat grayak \\
\hline P04 & Leaf miner \\
\hline P05 & Busuk daun \\
\hline P06 & Akar gada \\
\hline P07 & Bercak daun \\
\hline P08 & Busuk alternaria \\
\hline P09 & Kutu daun \\
\hline
\end{tabular}


Tabel 2. Gejala penyakit Tanaman Sawi

\begin{tabular}{cl}
\hline \multirow{2}{*}{ Kode Gejala } & \multicolumn{1}{c}{ Gejala } \\
\hline G01 & Permukaan daun akar rusak \\
\hline G02 & Daun berlubang dan tidak rata \\
\hline G03 & Daun mongering \\
\hline G04 & Akar tanaman rusak \\
\hline G05 & Tanaman menjadi layu \\
\hline G06 & Tanaman menguning dan mati \\
\hline G07 & Daun menguning \\
\hline G09 & Daun berlubang dan tidak beraturan \\
\hline G010 & Terdapat bercak kuning hingga kecoklatan \\
\hline G011 & Daun mulai membusuk \\
\hline G012 & Akar mulai membusuk \\
\hline G013 & Akar tanaman kering \\
\hline G014 & Daun melengkung keatas kriting atau melintir \\
\hline G015 & Daun belang-belang \\
\hline G016 & Tanaman mati tiba-tiba \\
\hline G017 & Daun mulai layu dan mati \\
\hline G018 & Pertumbuhan terhambat atau kredil \\
\hline
\end{tabular}

\subsubsection{Penerapan Metode}

Teknik Forward Chaining diimplementasikan dengan menyusun rule IF part menuju THEN part. Dari jenis penyakit dan gejalanya maka aturan forward chaining yang digunakan dapat dilihat pada Tabel 3.

Tabel 3. Aturan

\begin{tabular}{|c|c|c|c|c|c|c|c|c|c|}
\hline Gejala Penyakit & P01 & P02 & P03 & P04 & P05 & P06 & P07 & P08 & P09 \\
\hline G01 & $\sqrt{ }$ & & & & & & & & \\
\hline G02 & $\sqrt{ }$ & & & & & & & & \\
\hline G03 & $\sqrt{ }$ & & & & & & & & \\
\hline G04 & & $\sqrt{ }$ & & & & & & & \\
\hline G05 & & $\sqrt{ }$ & & $\sqrt{ }$ & & $\sqrt{ }$ & & & \\
\hline G06 & & $\sqrt{ }$ & & & & & & & \\
\hline G07 & & & $\sqrt{ }$ & & $\sqrt{ }$ & & & & $\sqrt{ }$ \\
\hline G08 & & & $\sqrt{ }$ & $\sqrt{ }$ & & & & & \\
\hline G09 & & & & $\sqrt{ }$ & & & $\sqrt{ }$ & & \\
\hline G010 & & & & & $\sqrt{ }$ & & & & \\
\hline G011 & & & & & $\sqrt{ }$ & & & & \\
\hline G012 & & & & & & $\sqrt{ }$ & & $\sqrt{ }$ & \\
\hline G013 & & & & & & $\sqrt{ }$ & & $\sqrt{ }$ & \\
\hline G014 & & & & & & & & & $\sqrt{ }$ \\
\hline G015 & & & & & & & & & $\sqrt{ }$ \\
\hline G016 & & & & $\sqrt{ }$ & & $\sqrt{ }$ & & $\sqrt{ }$ & \\
\hline G017 & & & & & & & $\sqrt{ }$ & & \\
\hline G018 & & & & & & & & \\
\hline
\end{tabular}

\subsection{Perancangan Sistem} Gambar 3.

Use case diagram sistem dapat dilihat pada Gambar 2. Sedangkan activity diagram dapat dilihat pada 


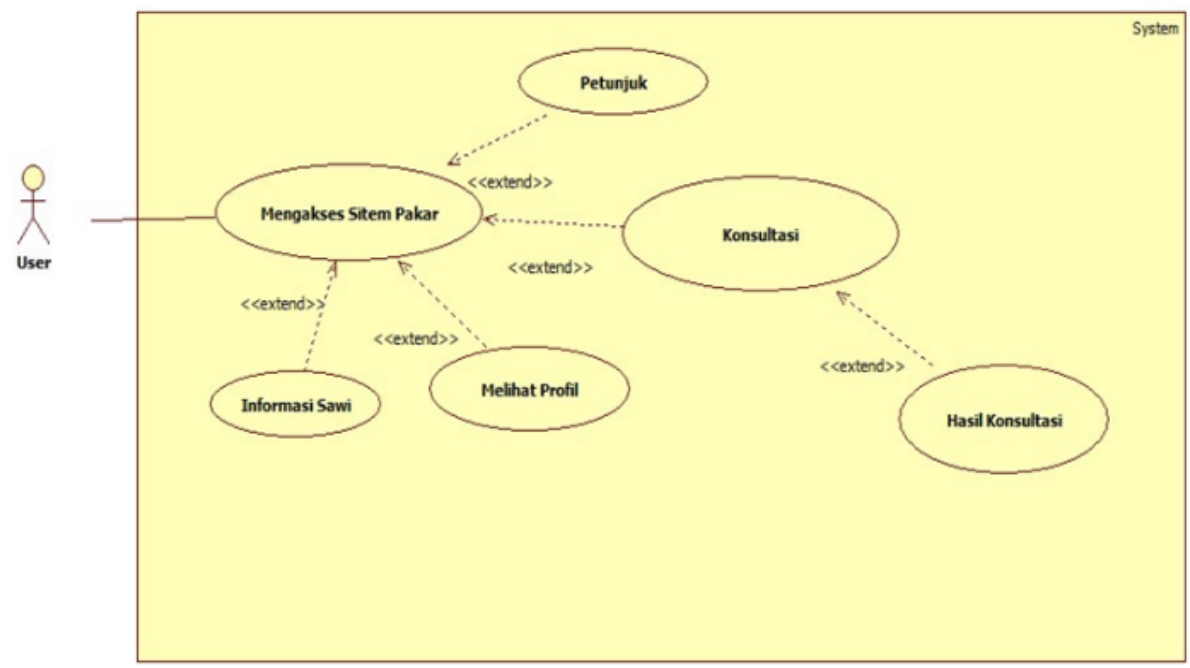

Gambar 2. Use Case Diagram Sistem

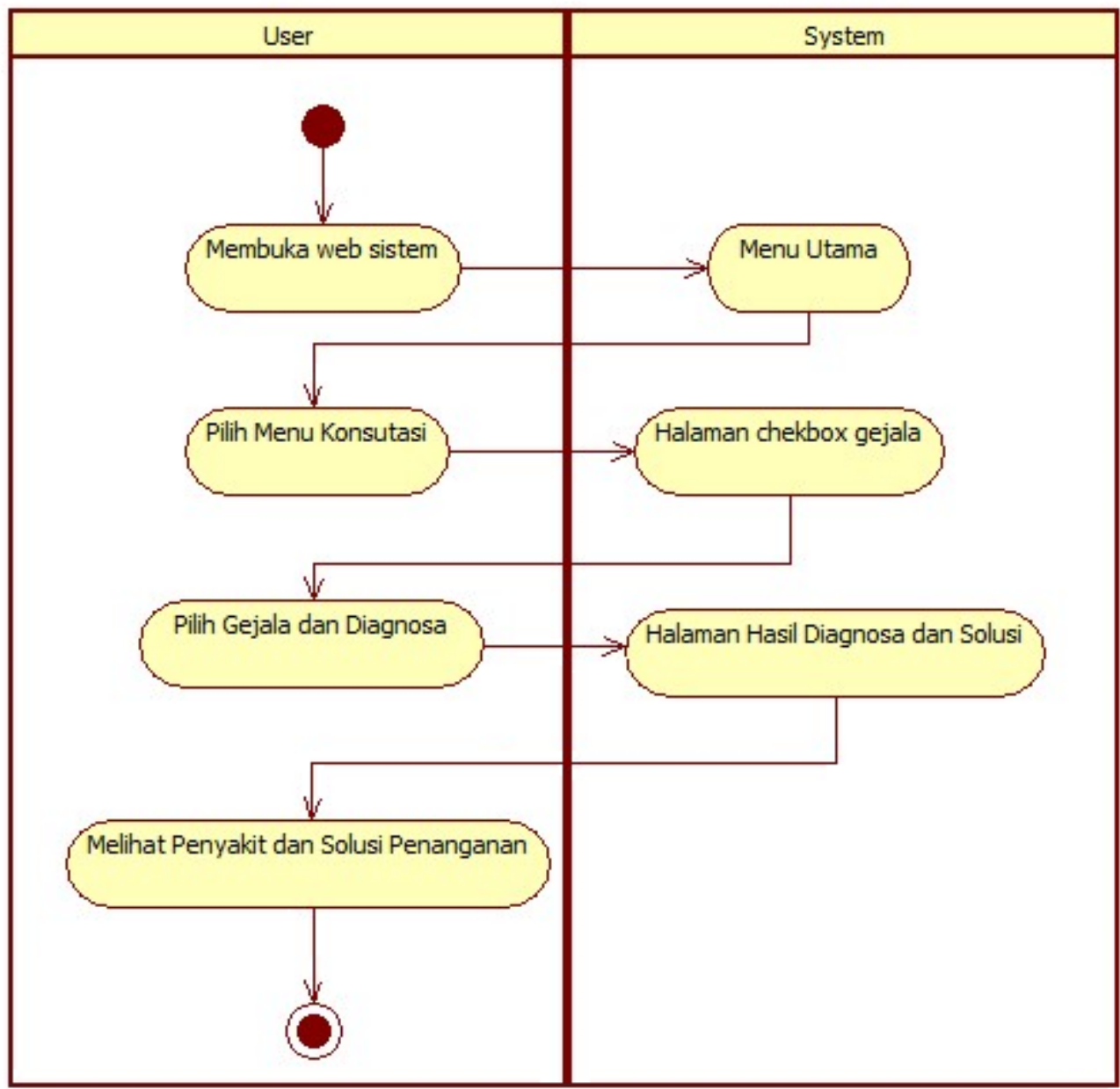

Gambar 3. Activity Diagram Sistem 


\section{Result and Analysis}

\subsection{Implementasi}

Implementasi adalah penerapan cara kerja sistem berdasarkan hasil analisa dan juga perancangan yang telah dibuat sebelumnya ke dalam suatu bahasa pemrograman tertentu. Tahap ini merupakan tahap dimana aplikasi siap untuk dioperasikan.

\subsubsection{Menu Utama}

Menu utama yang terdapat pada web sistem pakar ini menampilkan sub menu yaitu home, informasi sawi, konsultasi, petunjuk, profil seperti pada Gambar 4 berikut.

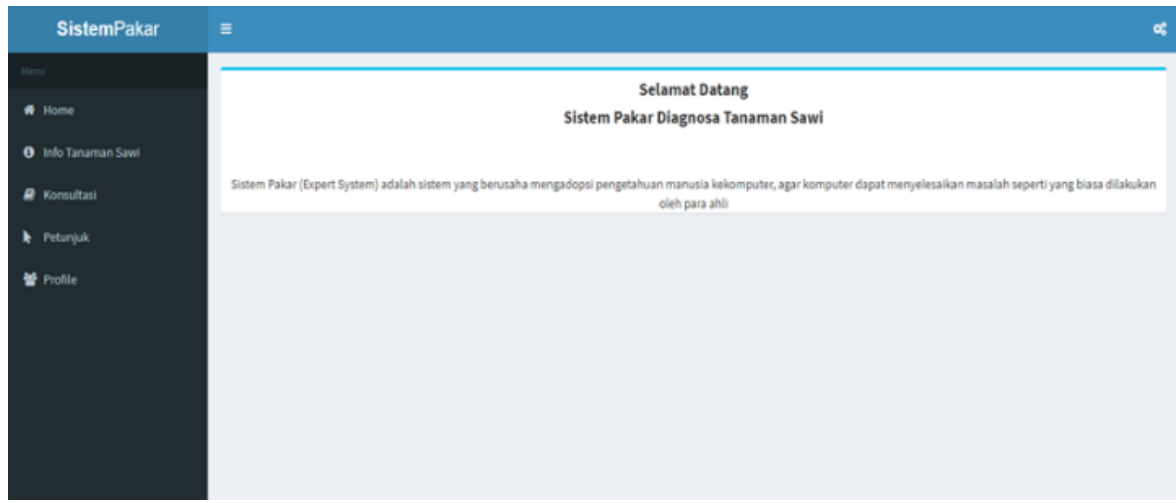

Gambar 4. Tampilan Menu Utama

\subsubsection{Menu Info Tanaman Sawi}

Pada menu info tanaman sawi ini bersikan tentang informasi mengenai tanaman sawi seperti pada Gambar 5

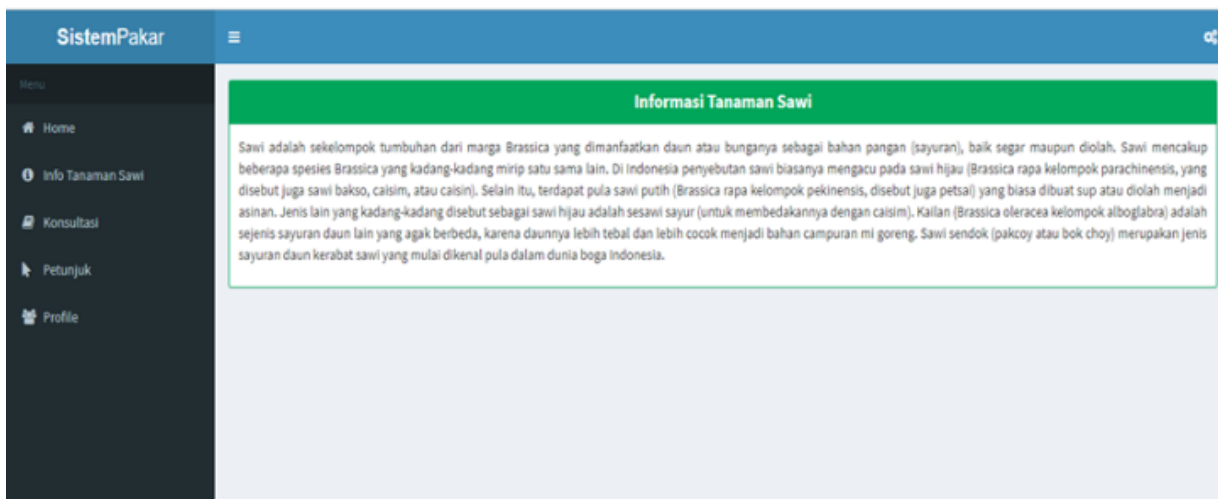

Gambar 5. Tampilan Informasi Tanaman Sawi

\subsubsection{Menu Konsultasi}

Menu konsultasi berupa data gejala yang diajukan sistem kepada pengguna kemudian user menceklis gejala dari tiap penyakit yang akan didiagnosa, pada hasil akhir akan terdapat kesimpulan dari tiap jawaban pengguna tentang penyakit yang dialami oleh tanaman sawi tersebut seperti pada Gambar 6 .

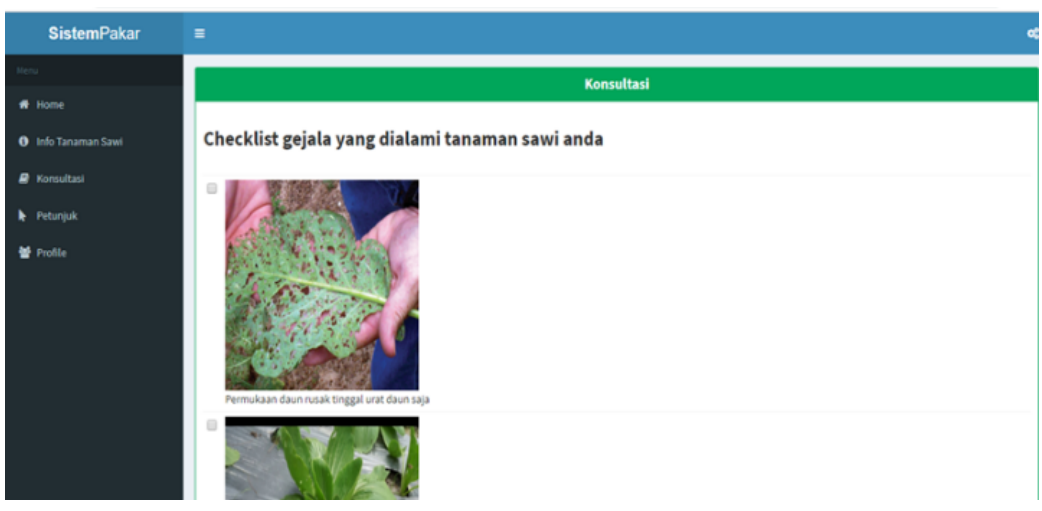


Gambar 6. Tampilan Menu Konsultasi

Setelah sistem menampilkan gejala penyakit kemudian pengguna menceklis jawaban dari tiap gejala yang ditimbulkan maka sistem akan menampilkan kesimpulan tentang penyakit yang sedang dialami oleh tanaman sawi tersebut seperti pada Gambar 7.

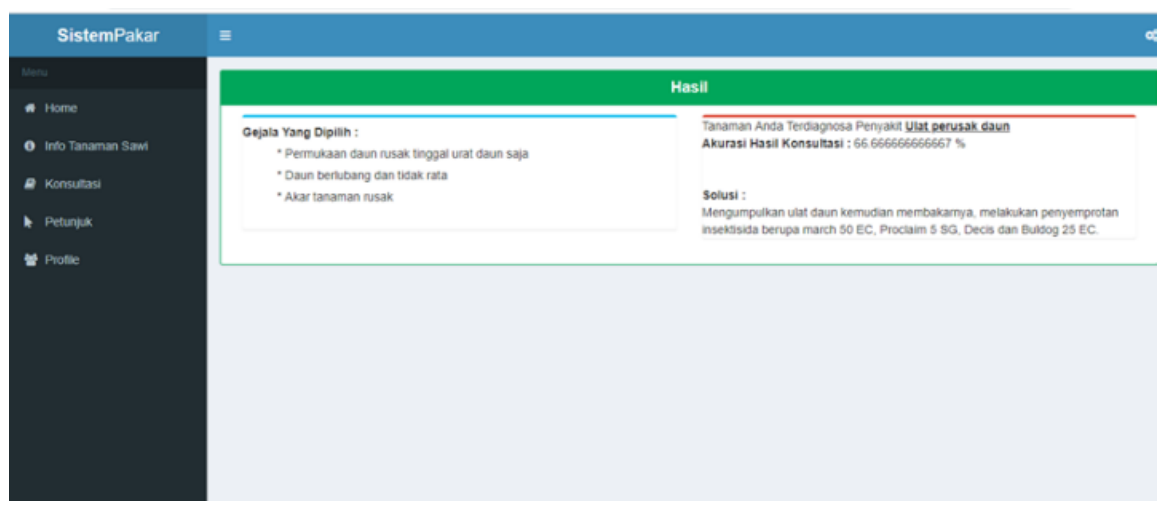

Gambar 7. Tampilan Hasil Konsultasi

\subsubsection{Menu Petunjuk}

Menu petunjuk adalah menu yang menampilkan cara penggunaan dari sistem pakar berbasis web yang dibuat, seperti pada Gambar 8.

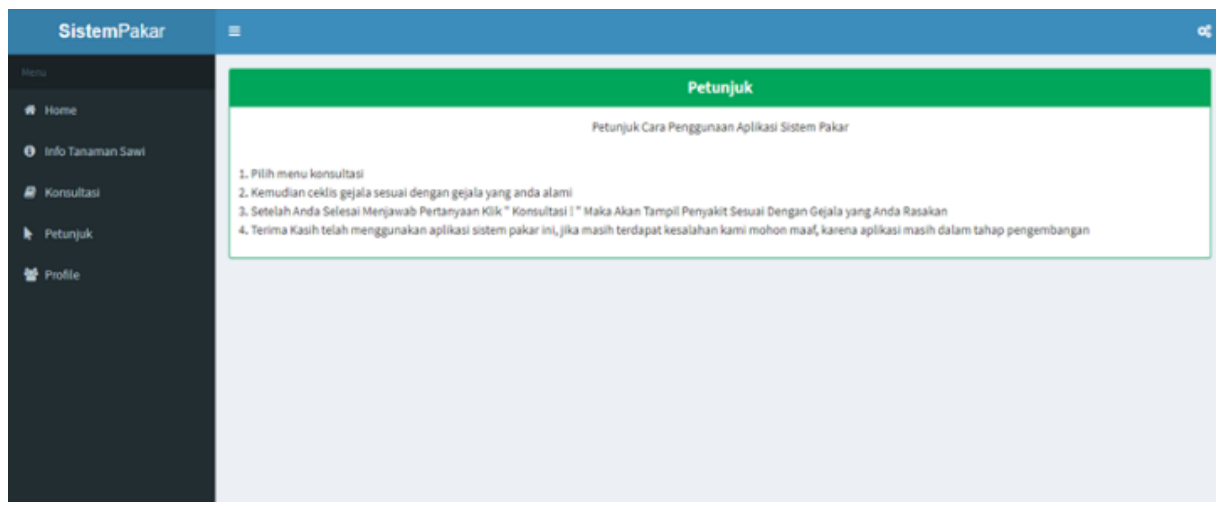

Gambar 8. Tampilan Menu Pentunjuk

\subsection{Pengujian}

Pengujian dilakukan sebanyak satu kali oleh pakar untuk melihat kesesuaian hasil dengan cara membandingkan diagnosis sistem pakar menggunakan metode forward chaining yang dikembangkan dengan diagnosis dari pakar. Hasil pengujian dapat dilihat pada Tabel 4.

Tabel 4. Hasil Perbandingan Pengujian Sistem Dengan Pakar

\begin{tabular}{|c|c|c|c|c|}
\hline No & Gejala & Sistem Pakar & Pakar & Status \\
\hline 1 & $\begin{array}{ll}\text { - } & \text { Permukaan daun akar rusa } \\
\text { - } & \text { Daun berlubang dan tidak rata } \\
\text { - } & \text { Daun mengering } \\
\end{array}$ & $\begin{array}{c}\text { Ulat perusak } \\
\text { daun }\end{array}$ & $\begin{array}{c}\text { Ulat perusak } \\
\text { daun }\end{array}$ & Akurat \\
\hline 2 & $\begin{array}{ll}\text { - } & \text { Akar tanaman rusak } \\
\text { - } & \text { Tanaman menjadi layu } \\
\text { - } & \text { Tanaman menguning dan mati }\end{array}$ & Ulat tanah & Ulat tanah & Akurat \\
\hline 3 & $\begin{array}{ll}\text { - } & \text { Daun menguning } \\
\text { - } & \text { Daun berlubang dan tidak beraturan } \\
\end{array}$ & Ulat grayak & Ulat grayak & Akurat \\
\hline 4 & $\begin{array}{ll}\text { - } & \text { Daun meguning } \\
\text { - } & \text { Terdapat bercak kuning hingga kecoklatan } \\
\text { - } & \text { Tanaman menjadi layu } \\
\text { - } & \text { Tanaman mati tiba-tiba }\end{array}$ & Leaf miner & Leaf miner & Akurat \\
\hline
\end{tabular}




\begin{tabular}{|c|c|c|c|c|}
\hline No & Gejala & Sistem Pakar & Pakar & Status \\
\hline 5 & $\begin{array}{ll}\text { - } & \text { Daun menguning } \\
\text { - } & \text { Terdapat lendir pada daun } \\
\text { - } & \text { Daun mulai membusuk } \\
\end{array}$ & Busuk daun & Busuk daun & Akurat \\
\hline 6 & $\begin{array}{l}\text { - } \quad \text { Akar mulai membusuk } \\
\text { - } \quad \text { Akar tanaman kering } \\
\text { - } \quad \text { Tanaman menjadi layu } \\
\text { - } \quad \text { Tanaman mati tiba-tiba }\end{array}$ & Akar gada & Akar gada & Akurat \\
\hline 7 & $\begin{array}{l}\text { - Terdapat bercak kuning hingga kecoklatan } \\
\text { - Daun mulai layu dan mati }\end{array}$ & Bercak daun & Bercak daun & Akurat \\
\hline 8 & $\begin{array}{ll}\text { - } & \text { Akar tanaman kering } \\
\text { - } & \text { Akar tanaman membusuk } \\
\text { - } & \text { Tanaman mati tiba-tiba }\end{array}$ & $\begin{array}{l}\text { Busuk } \\
\text { alternaria }\end{array}$ & Akar gada & Tidak Akurat \\
\hline 9 & $\begin{array}{ll}\text { - } & \text { Daun melengkung keatas kriting atau } \\
& \text { meleintir } \\
\text { - } & \text { Daun menguning } \\
\text { - } & \text { Daun belang-belang } \\
\text { - } & \text { Pertumbuhan terhambat atau kerdil }\end{array}$ & Kutu daun & Kutu daun & Akurat \\
\hline
\end{tabular}
berikut :

Maka untuk mengetahui hasil tingkat keakurasian sistem pada kasus diatas, maka perhitungannya sebagai

$$
\begin{aligned}
& \text { Nilai keakuratan }=\frac{\text { jumlah yang sesuai }}{\text { jumlah kasus }} \% \\
& \text { Nilai keakuratan }=\frac{8}{9} x \%=88,8 \%
\end{aligned}
$$

Dari hasil diatas maka disimpulkan bahwasanya aplikasi ini layak untuk dipakai dengan tingkat kekurasian mencapai $88,8 \%$.

\section{Conclusion}

Berdasarkan penelitian yang sudah dilakukan maka dapat diambil kesimpulan yaitu:

1. Sistem ini hanya dapat digunakan untuk mendiagnosa 9 jenis hama dan penyakit penyakit tanaman sawi. Untuk penelitian selanjutnya dapat dikembangkan sistem yang dapat mendiagnosa lebih dari 9 jenis hama dan penyakit serta 18 gejala tanaman sawi.

2. Hasil dalam penelitian ini terdapat kesesuaian hasil diagnosis sistem pakar menggunakan metode forward chaining dengan pakar. Akurasi metode forward chaining untuk diagnosis penyakit pada tanaman sawi adalah sebesar 88,8 \%. Dari hasil pengujian 88.8\% maka dapat disimpulkan bahwa aplikasi layak atau siap digunakan.

Untuk penelitian selanjutnya, aplikasi ini disarankan untuk dikembangkan lagi dengan metode yang baru seperti navy bayes, dempster shafer, certainlty factor dan lain-lain agar hasil yang didapat nantinya lebih maksimal.

\section{References}

[1] Rahmat Rukmana, BERTANAM PETSAI \& SAWI. Yogyakarta: Kanisius, 1994.

[2] H. Sunarjono, Bertanam Sawi dan Selada. Jakarta: Penebar Swadaya, 2004.

[3] F. Nainggolan, H. D. Hutahaean, and A. Gea, "Sistem Pakar Mendeteksi Penyakit Pada Tanaman Sayur Sawi Dengan Metode Bayes," vol. 2, no. 1, pp. 1-11, 2018.

[4] P. SIREGAR, "hama tanaman sawi," MEDAN, 2014.

[5] Ginanjar Wiro Sasmito, "Aplikasi Sistem Pakar Untuk Simulasi Diagnosa Hama Dan Penyakit Tanaman Bawang Merah Dan Cabai Menggunakan Forward Chaining Dan Pendekatan Berbasis Aturan," Tesis, no. sistem pakar, pp. 1-78, 2010.

[6] N. Nonci, "Bioekologi dan Pengendalian Pengorok Daun Liriomyza chinensis Kato (Diptera: Agromyzidae) pada Bawang Merah," Bioekol. dan Pengendali. Pengorok Daun Liriomyza chinensis Kato (Diptera Agromyzidae) pada Bawang Merah, vol. 30, no. 4, pp. 148-155, 2016, doi: 10.21082/jp3.v30n4.2011.p148-155.

[7] S.- Purwantisari, R. S. Ferniah, and B.- Raharjo, "Pengendalian Hayati Penyakit Hawar Daun Tanaman Kentang Dengan Agens Hayati Jamur-jamur Antagonis Isolat Lokal,” Bioma Berk. Ilm. Biol., vol. 10, 
no. 2, p. 51, 2012, doi: 10.14710/bioma.10.2.51-57.

[8] F. Towaki, "Insiden penyakit akar gada pada tanaman kubis di desa rurukan dan Kumelembuy kecamatan Tomohon timur kota Tomohon," vol. 53, p. 160, 2014, doi: 10.1017/CBO9781107415324.004.

[9] T. Suganda and D. Y. Wulandari, "Curvularia sp. Jamur Patogen Baru Penyebab Penyakit Bercak Daun pada Tanaman Sawi," Agrikultura, vol. 29, no. 3, p. 119, 2019, doi: 10.24198/agrikultura.v29i3.22716.

[10] T. Pratama, G. Suastika, and A. Nurmansyah, "Dampak Penyakit Tanaman terhadap Pendapatan Petani Kubis-kubisan di Daerah Agropolitan Kabupaten Cianjur, Jawa Barat,” J. Fitopatol. Indones., vol. 12, no. 6, p. 218, 2017, doi: 10.14692/jfi.12.6.218.

[11] R. Ramadhona, D. Djamilah, and M. Mukhtasar, "Efektivitas Ekstrak Daun Pepaya Dalam Pengendalian Kutu Daun Pada Fase Vegetatif Tanaman Terung," J. Ilmu-Ilmu Pertan. Indones., vol. 20, no. 1, pp. 1-6, 2018, doi: 10.31186/jipi.20.1.1-6.

[12] F. D. Saputra and H. Mustafidah, "Sistem Pakar Menentukan Tingkat Kecocokan Lahan Untuk Tanaman Jati Menggunakan Metode Forward Chaining (The Expert System Determine About Fitting Grade Of The Field For Tectonic Grandis By Forward Chaining Methode)," Juita, vol. IV, pp. 37-47, 2016.

[13] I. Siahaan, "Perbandingan Metode Certainty Factor Dan Bayes Dalam Mendiagnosa Penyakit Angina Pektoris Menggunakan Metode Perbandingan Eksponensial," Pelita Inform. Inf. dan Inform., vol. 16, no. 4, pp. 391-397, 2017, [Online]. Available: https://ejurnal.stmikbudidarma.ac.id/index.php/pelita/article/view/580/552. 